\title{
Rasionalitas Terapi Antibiotik Empiris Pada Pasien Pneumonia di Instalasi Rawat Inap RSUP Dr. Kariadi Semarang
}

\author{
Rationality of Empirical Antibiotic Therapy in Patients with Pneumonia in the \\ Inpatient Ward of Dr. Kariadi State Hospital in Semarang
}

Achmad Quraisy Aljufri1, Nanang Munif Yasin ${ }^{2 *}$, Djoko Wahyono

${ }_{1}^{1}$ Mahasiswa Magister Farmasi Klinik, Fakultas Farmasi Universitas Gadjah Mada

2 Departemen Farmakologi dan Farmasi Klinik, Fakultas Farmasi, Universitas Gadjah Mada

Corresponding author: Nanang Munif Yasin: Email: nanangy@yahoo.com

Submitted: 23-01-2020 Revised: 21-04-2020 Accepted: 11-05-2020

\begin{abstract}
ABSTRAK
Pneumonia adalah infeksi saluran pernafasan bagian bawah yang dapat diperoleh di lingkungan komunitas atau rumah sakit. Di Indonesia sendiri terdapat peningkatan prevalensi pneumonia dari 1,6\% (2013) menjadi 2,0\% (2018), dengan prevalensi di provinsi Jawa Tengah adalah sebesar 1,8\% (2018). Hal ini disebabkan oleh banyaknya pemberian antibiotik empiris yang tidak rasional. Penelitian ini bertujuan untuk mengetahui rasionalitas terapi antibiotik empiris serta hubungannya dengan clinical outcomes pasien dengan pneumonia di Instalasi Rawat Inap RSUP Dr. Kariadi Semarang. Penelitian ini menggunakan desain cross-sectional retrospektif untuk meneliti rasionalitas terapi antibiotik empiris pada pasien pneumonia di Instalasi Rawat Inap RSUP Dr. Kariadi Semarang. Sampel yang diambil adalah seluruh pasien dengan pneumonia selama periode Januari 2017-Juli 2019. Analisis terhadap rasionalitas terapi antibiotik empiris dilakukan dengan menggunakan kategori Gyssens dan dilanjutkan dengan uji Chi-square. Terdapat 98 pasien yang diuji pada penelitian ini. Sebanyak 87 pasien telah diberikan terapi antibiotik empiris rasional dengan $77,01 \%$ clinical outcomes pasien dinyatakan membaik dan sebanyak 11 pasien telah diberikan terapi antibiotik empiris tidak rasional dengan 54,55\% clinical outcomes pasien dinyatakan membaik. Hasil analisis statistik menunjukkan bahwa tidak ada hubungan antara rasionalitas terapi antibiotik empiris dengan clinical outcomes dari pasien yang menjalani rawat inap akibat pneumonia di RSUP Dr. Kariadi Semarang $(\mathrm{p}=0,107)$.
\end{abstract}

Kata kunci: pneumonia; rasionalitas; antibiotik empiris; clinical outcomes

\begin{abstract}
Pneumonia is a lower respiratory tract infection that can be acquired in a community or hospital setting. In Indonesia, there has been an increase in the prevalence of pneumonia over the past few years from 1,6\% (2013) to 2,0\% (2018), with 1,8\% of the prevalence being in Central Java. This is caused by the administration of irrational empirical antibiotics. This study aims to determine the rationality of empirical antibiotic therapy and its relationship with the clinical outcome of patients with pneumonia in the Inpatient Ward of Dr. Kariadi State Hospital in Semarang. This study uses a cross-sectional design to retrospectively examine the rationality of empirical antibiotic therapy in pneumonia patients. Samples taken were all patients with pneumonia during the period of January 2017-July 2019. Analysis of the rationality of empirical antibiotic therapy was conducted using the Gyssens category and continued with Chi-square test. There were 98 patients enrolled in this study. 87 patients were given rational empirical antibiotics with $77,01 \%$ shown good clinical outcomes and 11 patients were given irrational empirical antibiotics with 54,55\% shown good clinical outcomes. Statistical analysis showed that there was no relationship between the rationality of empirical antibiotics therapy and the clinical outcome of patients with pneumonia $(\mathrm{p}=0,107)$.
\end{abstract}

Keywords: pneumonia; rationality; empirical antibiotics; clinical outcome 


\section{PENDAHULUAN}

Pneumonia adalah sindrom klinis paruparu dengan berbagai tingkat keparahan, sering bermanifestasi dalam bentuk batuk, demam, dan kesulitan dalam bernafas. Hal tersebut disebabkan oleh mikroba patogen, meskipun etiologi tidak diidentifikasi dalam sebagian besar kasus. Pencegahan dan pengobatan untuk pneumonia tergantung pada lokasi dimana infeksi diperoleh (Corrado dkk., 2017). Pneumonia dapat diperoleh di lingkungan komunitas/masyarakat atau di lingkungan rumah sakit, dan penularannya dapat melalui aspirasi maupun inhalasi mikroba patogen (Cilloniz dkk., 2016).

Di Indonesia terdapat peningkatan prevalensi pneumonia (berdasarkan diagnosis dokter) dari 1,6\% (2013) menjadi 2,0\% (2018). Enam provinsi yang mempunyai prevalensi pneumonia tertinggi untuk semua umur di tahun 2018 adalah Papua (3,6\%), Bengkulu $(3,4 \%)$, Papua Barat (2,9\%), Jawa Barat $(2,6 \%)$, dan Aceh (2,5\%). Untuk di provinsi Jawa Tengah, prevalensinya adalah sebesar 1,8\% (Kemenkes, 2018). Berdasarkan Guideline Community-acquired Pneumonia (CAP) untuk pasien dewasa, terapi antibiotik empiris dapat digunakan bagi pasien rawat jalan, rawat inap maupun ICU. Lama pemberian antibiotik pada pasien dewasa dengan CAP bergantung pada perkembangan klinis pasien dan terapi antibiotik harus diteruskan sampai pasien mencapai kondisi klinis yang stabil selama tidak kurang dari 5 hari (Metlay dkk., 2019). Pada pasien Hospital-acquired Pneumonia (HAP) perlu dilakukan identifikasi terkait kemungkinan adanya faktor risiko untuk multidrug-resistant organisms (MDRO) karena akan mempengaruhi pemberian antibiotik empiris yang tepat (Kalil dkk., 2016).

Penelitian ini bertujuan untuk memperoleh gambaran mengenai rasionalitas dari pemberian terapi antibiotik empiris serta hubungannya terhadap clinical outcomes pasien dengan penyakit pneumonia yang telah menjalani rawat inap di salah satu rumah sakit rujukan nasional di Jawa Tengah yaitu RSUP Dr. Kariadi Semarang.

\section{METODOLOGI}

Penelitian ini menggunakan desain crosssectional dengan melakukan pengambilan data secara retrospektif berdasarkan rekam medis pasien pneumonia selama bulan Juni-Juli 2019.
Terdapat 98 pasien yang diuji pada penelitian ini. Populasi pada penelitian ini adalah pasien dengan penyakit pneumonia yang telah menjalani rawat inap di RSUP Dr. Kariadi Semarang dan telah mendapatkan terapi antibiotik empiris selama rawat inap. Sampling dilakukan dengan metode purposive sampling pada seluruh pasien dengan pneumonia di Instalasi Rawat Inap RSUP Dr. Kariadi Semarang selama periode Januari 2017-Juli 2019 yang memenuhi kriteria inklusi yaitu pasien laki-laki atau perempuan pada periode 1 Januari 201730 Juli 2019 dengan diagnosis pneumonia yang sudah ditegakkan saat rawat inap, kategori usia dewasa (18-60 tahun) dan lansia ( $>60$ tahun) yang menjalani lama rawat inap selama $>72$ jam setelah admisi rumah sakit, telah diberikan terapi antibiotik empiris sejak admisi rumah sakit dan data rekam medis lengkap meliputi identitas pasien (nama, tanggal lahir, jenis kelamin, berat badan, tinggi badan), nomor rekam medis, tanggal masuk dan keluar rumah sakit, riwayat penyakit, riwayat alergi obat, riwayat pengobatan, tanda-tanda vital, hasil pemeriksaan laboratorium (radiologi, kultur mikrobiologi), diagnosis, data antibiotik (jenis, rute, dosis, interval, durasi terapi) dan clinical outcome pasien. Kriteria eksklusi pada penelitian ini adalah pasien meninggal sebelum menerima antibiotik empiris $<2$ hari dan pasien perempuan yang sedang dalam masa kehamilan atau menyusui. Penanganan sampel dengan missing data pada penelitian ini adalah dengan cara dilakukan penghapusan.

Variabel bebas dalam penelitian ini adalah rasionalitas terapi antibiotik empiris, variabel tergantung adalah clinical outcomes pasien pneumonia setelah minimal 2 hari pemberian antibiotik empiris. Confounders pada penelitian ini adalah adanya komorbiditas seperti DM, sepsis atau penyakit lainnya dan adanya riwayat gangguan ginjal. Penilaian terhadap rasionalitas terapi antibiotik empiris dilakukan dengan menggunakan kategori Gyssens. Antibiotik empiris dikatakan rasional apabila tergolong dalam kategori 0 dan dikatakan tidak rasional apabila tergolong dalam kategori I-VI. Antibiotik empiris tergolong dalam kategori IV apabila data pada rekam medis pasien tidak lengkap; tergolong kategori $\mathrm{V}$ apabila tidak ada indikasi pasien untuk diberikan antibiotik dalam rekam medis pasien; tergolong kategori IVa atau IVb atau IVd apabila antibiotik tidak tepat dari segi 


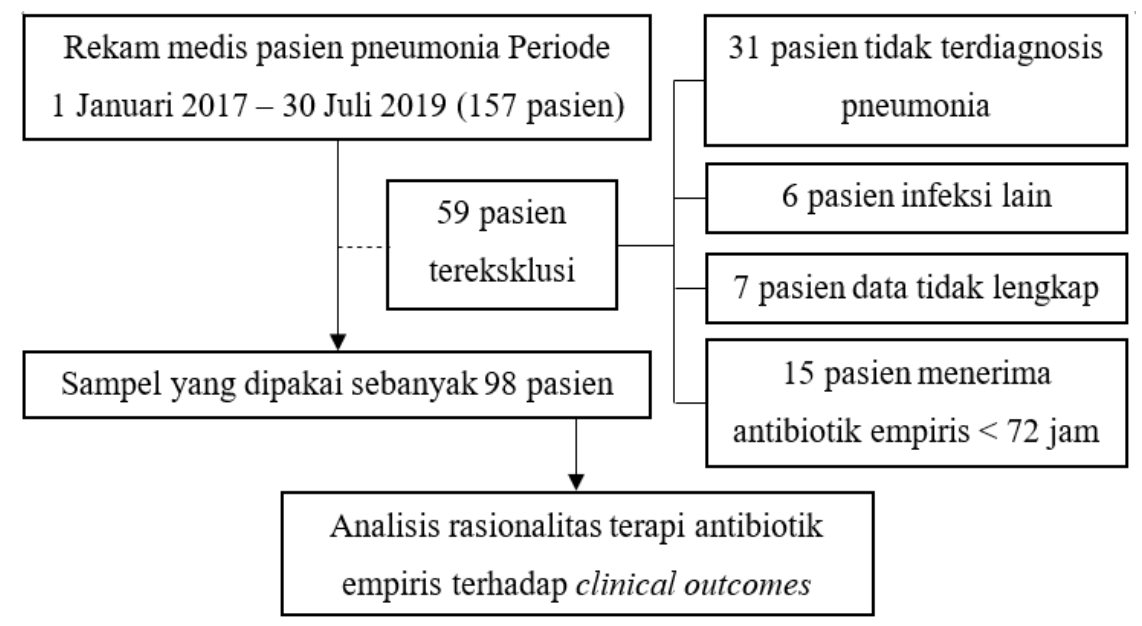

Gambar 1. Alur pengambilan data

efektivitas, toksisitas dan luas spektrum berdasarkan Pedoman Penggunaan Antibiotik (PPAB) dan Guideline CAP/HAP; tergolong kategori IIIa atau IIIb apabila lama pemberian antibiotik terlalu lama atau terlalu singkat menurut PPAB dan Drug Information Handbook (DIH); tergolong kategori IIa atau IIb atau IIc apabila dosis, interval, atau rute pemberian antibiotik tidak tepat menurut DIH; dan digolongkan kategori I apabila waktu pemberian antibiotik kepada pasien tidak tepat menurut Guideline CAP/HAP atau DIH. Clinical outcomes pasien diukur berdasarkan catatan dokter di rekam medis dinyatakan dalam keterangan membaik, belum membaik, atau meninggal.

Analisis deskriptif dilakukan untuk melihat data demografi pasien (jenis kelamin dan usia), angka kejadian pneumonia selama periode yang ditetapkan, komorbiditas/penyakit penyerta dan clinical outcomes pasien. Untuk mengetahui hubungan antara rasionalitas antibiotik empiris terhadap clinical outcomes dilakukan analisis uji Chisquare dengan interval kepercayaan (Confidence Interval) sebesar 95\% $(\alpha=5 \%)$ menggunakan program SPSS untuk Windows versi 24.

\section{HASIL DAN PEMBAHASAN}

Pada penelitian ini jumlah sampel yang didapatkan pada periode Januari 2017-Juli 2019 ialah sebanyak 157 pasien. Setelah disesuaikan dengan kriteria penelitian, didapatkan sebanyak 98 pasien yang memenuhi kriteria inklusi. Pada penelitian ini terdapat sebanyak 7 pasien dengan missing data sehingga sampel tersebut tidak diteliti dengan cara dieksklusikan. Alur pengambilan data dapat dilihat pada Gambar 1 .

\section{Karakteristik Subjek}

Berdasarkan data karakteristik pasien pada tabel I, jumlah pasien dengan pneumonia lebih banyak terjadi pada kategori usia lansia (> 60 tahun) dengan persentase sebesar $59,18 \%$. Bertambahnya usia adalah faktor risiko utama untuk pneumonia. Pada usia dewasa, angka kejadian tahunan berkisar dari 1,07 hingga 14 per 1.000 orang setiap tahunnya dan tidak banyak berubah dalam beberapa dekade terakhir (Lopardo dkk., 2018).

Pasien dengan jenis kelamin laki-laki (52,04\%) lebih banyak mengalami kejadian pneumonia dibandingkan dengan perempuan (47,96\%). Dalam suatu penelitian di Asia, kejadian tahunan untuk CAP diperkirakan sebesar 16,9 kasus per 1.000 orang per tahun, lebih sering terjadi pada pria daripada wanita untuk semua kelompok usia (15,6 vs. 9,3 per 1.000 orang per tahun) (Cillóniz dkk., 2018).

Persentase komorbiditas tertinggi pada penelitian ini adalah hipertensi $(28,03 \%)$ diikuti dengan gagal jantung (19,7\%), diabetes mellitus $(15,91 \%)$, gangguan ginjal $(15,15 \%)$, tuberkulosis $(6,06 \%)$, penyakit paru obstruktif kronis $(6,06 \%)$, kanker $(4,54 \%)$, stroke $(3,79 \%)$ dan sepsis (0,76\%). Selain faktor usia, komorbiditas yang ada pada pasien juga berperan penting dalam menentukan risiko maupun tingkat keparahan pneumonia. Oleh karena itu, pasien dengan penyakit penyerta seperti diabetes mellitus, kanker, gagal jantung kronis, penyakit paru obstruktif kronis, 
Tabel I. Karakteristik Pasien Pneumonia di RSUP Dr. Kariadi

\begin{tabular}{lcc}
\hline Karakteristik & \multicolumn{2}{c}{ Jumlah Pasien } \\
\cline { 2 - 3 } & (n = 98) & \% \\
\hline Usia & & \\
18-60 tahun & 40 & 40,82 \\
> 60 tahun & 58 & 59,18 \\
Jenis Kelamin & & \\
Laki-laki & 51 & 52,04 \\
Perempuan & 47 & 47,96 \\
Komorbiditas & & \\
Hipertensi & 37 & 33,04 \\
Gagal Jantung & 26 & 23,21 \\
Diabetes Mellitus & 21 & 18,75 \\
Gangguan Ginjal & 20 & 17,86 \\
Tuberkulosis & 8 & 7,14 \\
CCI & & \\
$\leq 3$ & 56 & 57,14 \\
$>3$ & 42 & 42,86 \\
\hline
\end{tabular}

Ket.: $\mathrm{CCI}=$ Charlson Comorbidity Index; satu pasien dapat menderita lebih dari satu komorbiditas

Tabel II. Pola Pemberian Antibiotik di RSUP Dr. Kariadi

\begin{tabular}{lcc}
\hline \multicolumn{1}{c}{ Antibiotik } & Jumlah & $\mathbf{\%}$ \\
\hline Seftriakson & 37 & 37,76 \\
Ampisilin-sulbaktam & 32 & 32,65 \\
Levofloksasin & 20 & 20,41 \\
Ciprofloksasin & 3 & 3,06 \\
Gentamisin & 1 & 1,02 \\
Moksifloksasin & 1 & 1,02 \\
Sefoperazon-sulbaktam & 1 & 1,02 \\
Levofloksasin + gentamisin & 1 & 1,02 \\
Seftriakson + ciprofloksasin & 1 & 1,02 \\
Ampisilin-sulbaktam + gentamisin & 1 & 1,02 \\
TOTAL & $\mathbf{9 8}$ & $\mathbf{1 0 0 , 0}$ \\
\hline
\end{tabular}

Alzheimer, penyakit arteri koroner, fibrosis kistik, gangguan ginjal/dialisis ginjal, penyakit syaraf kronis, atau pun gangguan liver kronis lebih berisiko menderita pneumonia (Tejada dkk., 2018).

Penilaian CCI digunakan untuk melihat derajat komorbiditas pada pasien. Pada penelitian ini, kelompok dengan nilai $\mathrm{CCI} \leq 3$ memiliki jumlah yang lebih banyak $(57,14 \%)$ dibandingkan dengan kelompok dengan nilai CCI $>3(42,86 \%)$.

\section{Gambaran Penggunaan Antibiotik}

Dalam pemberian terapi antibiotik empiris pada pasien, RSUP Dr. Kariadi Semarang memiliki acuan utama yang digunakan yaitu
PPAB. Adapun sebaran antibiotik empiris yang digunakan pada pasien dengan pneumonia selama periode Januari 2017 hingga Mei 2019 di RSUP Dr. Kariadi Semarang dapat dilihat pada tabel II.

Jumlah sampel dengan CAP adalah 86 pasien sedangkan jumlah sampel dengan HAP adalah 12 pasien. Pada penelitian ini, sebanyak 95 pasien menerima terapi antibiotik empiris secara monoterapi sedangkan sebanyak 3 pasien menerima terapi antibiotik empiris secara kombinasi. Antibiotik yang paling banyak diberikan secara monoterapi adalah dari golongan sefalosporin, yaitu seftriakson sebanyak 37 pasien $(37,76 \%)$. Antibiotik dalam bentuk kombinasi seperti levofloksasin + 
Tabel III. Rasionalitas Antibiotik Empiris Berdasarkan Kategori Gyssens

\begin{tabular}{lc}
\hline \multicolumn{1}{c}{ Kategori Gyssens } & Jumlah Pasien \\
Rasional & $\mathbf{8 7}(\mathbf{8 8 , 7 8 )}$ \\
Kategori 0 & $\mathbf{1 1}(\mathbf{1 1 , 2 2 )}$ \\
Tidak Rasional & 0 \\
Kategori VI (data tidak lengkap) & 0 \\
Kategori V (tidak ada indikasi penggunaan antibiotik) & $5(5,10)$ \\
Kategori IVa (ada antibiotik lain yang lebih efektif) & 0 \\
Kategori IVb (ada antibiotik lain yang kurang toksik) & $0 *$ \\
Kategori IVc (ada antibiotik lain yang lebih murah) & 0 \\
Kategori IVd (ada antibiotik lain spektrum lebih sempit) & 0 \\
Kategori IIIa (penggunaan antibiotik terlalu lama) & 0 \\
Kategori IIIb (penggunaan antibiotik terlalu singkat) & $1(1,02)$ \\
Kategori IIa (dosis antibiotik tidak tepat) & $5(5,10)$ \\
Kategori IIb (interval pemberian antibiotik tidak tepat) & 0 \\
Kategori IIc (rute pemberian antibiotik tidak tepat) & 0 \\
Kategori I (waktu pemberian antibiotik tidak tepat) & \\
\hline
\end{tabular}

Ket.: *tidak dilakukan penilaian pada kategori IVc

gentamisin, seftriaxone + ciprofloksasin dan ampisilin-sulbaktam + gentamisin masingmasing diberikan kepada 1 pasien $(1,02 \%)$.

Penggunaan seftriakson sebagai terapi empiris hanya direkomendasikan oleh PPAB RSUP Dr. Kariadi Tahun 2018 untuk pasien dengan HAP akan tetapi pemberiannya justru paling banyak digunakan pada pasien dengan CAP. Menurut guideline CAP terbaru oleh IDSA, seftriakson merupakan salah satu antibiotik empiris yang dapat direkomendasikan pada pasien CAP tanpa faktor risiko MDRO namun dalam bentuk kombinasi dengan antibiotik golongan makrolida (Metlay dkk., 2019). Dari total 38 pasien, 16 pasien di tahun 2017 dan 22 pasien di tahun 2018 telah menerima seftriakson sebagai antibiotik empiris baik secara monoterapi atau pun kombinasi. Dari bulan Januari hingga Juli 2019, seftriakson belum pernah lagi diberikan sebagai terapi empiris baik pada pasien dengan CAP maupun HAP. Hal ini mungkin disebabkan oleh adanya perbedaan rekomendasi dari PPAB RSUP Dr. Kariadi sebelum tahun 2018 atau karena PPAB belum diterapkan secara menyeluruh untuk pasien di RSUP Dr. Kariadi Semarang.

\section{Rasionalitas Antibiotik Empiris Berdasarkan Kategori Gyssens}

Penilaian terkait rasionalitas antibiotik pada penelitian ini dilihat dari ketepatan indikasi, pemilihan obat, lama pemberian, dosis, interval, rute dan waktu pemberian yang ada pada kategori Gyssens (Permenkes, 2011). Acuan-acuan yang digunakan dalam melakukan analisis adalah PPAB Terapetik (RSUP Dr. Kariadi, 2018), Guideline CAP (Mandell dkk., 2007), Guideline HAP (Kalil dkk., 2016) dan DIH (American Pharmacists Association, 2018) untuk melihat setiap antibiotik yang dianalisis termasuk pada kategori berapa diantara kategori 0-VI. Jika antibiotik yang diberikan tidak tercantum dalam PPAB, maka penelusuran selanjutnya dilakukan dengan melihat Guideline CAP/HAP atau DIH. Rasionalitas antibiotik empiris yang dinilai dengan kategori Gyssens dapat dilihat pada tabel III.

Pada penelitian ini tidak ada pasien yang termasuk dalam kategori VI karena sampel dengan missing data sudah dieksklusikan. Seluruh sampel juga tidak ada yang termasuk dalam kategori $\mathrm{V}$ karena semua data pasien telah didiagnosis pneumonia yang menunjukkan adanya indikasi pemberian antibiotik. Tidak ada sampel yang termasuk dalam kategori IIIa dan IIIb karena durasi pemberian antibiotik pada seluruh pasien dianggap sudah sesuai dengan perkembangan klinis pasien. Tidak ada sampel yang termasuk dalam kategori I karena waktu pemberian antibiotik pada seluruh pasien yang diteliti dianggap sudah tepat.

Hasil analisis antibiotik empiris tersebut menunjukkan bahwa regimen antibiotik yang 
Tabel IV. Antibiotik Yang Tidak Rasional Berdasarkan Kategori Gyssens

\begin{tabular}{|c|c|c|}
\hline Kategori Gyssens & Antibiotik & Pneumonia \\
\hline \multirow{5}{*}{ IVa } & Levofloksasin + Gentamisin & CAP \\
\hline & Gentamisin & HAP \\
\hline & Ciprofloksasin & CAP \\
\hline & Sefoperazon-sulbaktam & CAP \\
\hline & Ampisilin-sulbaktam + Gentamisin & CAP \\
\hline \multirow[t]{3}{*}{ IIa } & Ciprofloksasin & HAP \\
\hline & Ampisilin-sulbaktam & CAP \\
\hline & Ampisilin-sulbaktam & CAP \\
\hline \multirow[t]{3}{*}{ IIb } & Ampisilin-sulbaktam & CAP \\
\hline & Ampisilin-sulbaktam & CAP \\
\hline & Ampisilin-sulbaktam & CAP \\
\hline
\end{tabular}

rasional terdapat sebanyak 87 regimen $(88,78 \%)$, sedangkan regimen antibiotik yang tidak rasional terdapat sebanyak 11 regimen $(11,22 \%)$. Antibiotik-antibiotik yang tidak rasional pada penelitian ini antara lain disebabkan oleh adanya antibiotik lain yang lebih efektif $(5,1 \%)$, dosis antibiotik yang tidak tepat $(1,02 \%)$ dan interval pemberian antibiotik yang tidak tepat $(5,1 \%)$. Hasil penelitian ini sama dengan penelitian yang dilakukan di RS Pendidikan Surabaya yang menunjukkan kategori IVa merupakan jumlah terbesar dalam penilaian dengan kategori Gyssens (Faizah dan Putra, 2019). Regimen antibiotik yang tidak rasional dapat dilihat pada tabel IV.

Ketidakrasionalan penggunaan antibiotik yang termasuk dalam kategori IVa terdapat sebanyak 5 regimen Menurut PPAB, antibiotik lini pertama yang dapat diberikan pada pasien CAP adalah levofloksasin atau ampisilinsulbaktam. penggunaan antibiotik golongan aminoglikosida seperti gentamisin hanya dapat direkomendasikan apabila pasien dengan CAP memiliki riwayat alergi terhadap antibiotik golongan penisilin sedangkan pada pasien dengan HAP, antibiotik ini dapat diberikan kepada pasien dengan faktor risiko patogen MDRO dalam bentuk kombinasi dengan piperasilin-tazobaktam atau levofloksasin/ciprofloksasin. Pemberian antibiotik empiris dengan sefoperazonsulbaktam juga dapat direkomendasikan untuk pasien dengan HAP saja (RSUP Dr. Kariadi, 2018).

Pada kategori IIa terdapat hanya 1 pasien yang menerima antibiotik empiris dengan dosis yang tidak tepat. Pasien ini mendapatkan antibiotik empiris dengan ciprofloksasin 200 mg/12 jam. Ciprofloksasin dapat menjadi pilihan terapi lini pertama untuk HAP dengan dosis 400 mg/8 jam (RSUP Dr. Kariadi, 2018). Pada kategori IIb terdapat sebanyak 5 pasien yang menerima antibiotik empiris dengan interval pemberian yang tidak tepat. Seluruh pasien tersebut menerima ampisilin-sulbaktam dengan dosis 1,5 gr/8 jam secara intravena untuk CAP. Alasan mengapa interval pemberian obat tersebut tidak tepat pada seluruh pasien tersebut adalah karena adanya gangguan pada fungsi ginjal. Menurut DIH, modifikasi dosis antibiotik ampisilin-sulbaktam pada pasien dengan gangguan ginjal tergantung pada nilai clearance creatinine $(\mathrm{ClCr})$ pasien tersebut. Apabila nilai $\mathrm{ClCr} \geq 30 \mathrm{~mL} / \mathrm{menit} / 1,73 \mathrm{~m}^{2}$ maka penyesuaian dosis tidak diperlukan, jika nilai ClCr 15-29 mL/menit/1,73 $\mathrm{m}^{2}$ maka dosis yang diberikan ialah 1,5-3 gr/12 jam dan jika nilai ClCr 5-14 mL/menit/1,73 $\mathrm{m}^{2}$ maka dosis yang diberikan ialah 1,5-3 gr/24 jam (American Pharmacists Association, 2018).

\section{Hubungan Rasionalitas Antibiotik Empiris Terhadap Clinical Outcomes}

Hasil penilaian rasionalitas terapi antibiotik empiris yang sudah dilakukan kemudian dicari hubungannya terhadap clinical outcomes pasien dengan pneumonia yang telah menjalani rawat inap di RSUP Dr. Kariadi Semarang. Hasil analisis hubungan antara kedua variabel tersebut dapat dilihat pada tabel V.

Tabel $\mathrm{V}$ menunjukkan tidak ada hubungan yang bermakna antara rasionalitas antibiotik empiris dengan clinical outcomes dengan nilai $\mathrm{p}$ sebesar 0,107 $(\mathrm{p}<0,05)$. Pasien yang menerima regimen terapi antibiotik empiris yang rasional ada sebanyak 87 pasien 
Tabel V. Hubungan Rasionalitas Antibiotik Empiris dan Clinical Outcomes

\begin{tabular}{lcccccc}
\hline \multirow{2}{*}{ Rasionalitas } & \multicolumn{2}{c}{ Clinical Outcomes } & \multirow{2}{*}{ Total } & \multirow{2}{*}{$\boldsymbol{P}$} & \multirow{2}{*}{ OR } & \multirow{2}{*}{$\mathbf{9 5 \%}$ CI } \\
\cline { 2 - 5 } & Membaik & Tidak Membaik & & & \\
Rasional & $67(77,01 \%)$ & $20(22,99 \%)$ & $87(88,78 \%)$ & & & \\
Tidak & $6(54,55 \%)$ & $5(45,45 \%)$ & $11(11,22 \%)$ & 0,107 & 2,79 & $0,77-10,12$ \\
Rasional & $\mathbf{7 3}$ & $\mathbf{2 5}$ & $\mathbf{9 8}$ & & & \\
TOTAL & & &
\end{tabular}

Ket. : OR = Odds Ratio $; \mathrm{CI}=$ Confidence Interval

$(88,78 \%)$ dengan clinical outcomes sebanyak 67 pasien $(77,01 \%)$ dinyatakan membaik dan 20 pasien $(22,99 \%)$ dinyatakan tidak membaik sedangkan pasien yang menerima regimen terapi antibiotik empiris yang tidak rasional ada sebanyak 11 pasien $(11,22 \%)$ dengan clinical outcomes sebanyak 6 pasien $(54,55 \%)$ dinyatakan membaik dan 5 pasien $(45,45 \%)$ dinyatakan tidak membaik. Pasien dengan antibiotik empiris yang rasional dapat memberikan clinical outcomes membaik sebanyak 2,79 kali dibandingkan pasien dengan antibiotik empiris yang tidak rasional $(\mathrm{p}=0,107$; $\mathrm{OR}=2,79 ; 95 \% \mathrm{CI}=0,77-10,12$ ). Hasil dari 95\% Confidence Interval adalah 0,77-10,12 yang menunjukkan bahwa tidak ada hubungan antara rasionalitas antibiotik empiris dengan clinical outcomes karena melewati angka satu. Hasil penelitian ini dapat digunakan pada populasi dengan karakteristik sampel yang menyerupai penelitian ini. Hasil yang sama juga ditemukan pada penelitian di tiga rumah sakit sekaligus antara lain RSUPN Dr. Cipto Mangunkusumo, RSUD Budhi Asih, dan RSPAD Gatot Soebroto. Pada penelitian tersebut tidak didapatkan adanya hubungan yang bermakna antara ketepatan pemberian antibiotik yang dinilai berdasarkan kategori Gyssens dengan perbaikan klinis pasien ( $\mathrm{p}=1,0 ; \mathrm{RR}=1,194 ; 95 \%$ CI=0,648-2,20) (Rumende dkk., 2019).

Keterbatasan dalam penelitian ini adalah susahnya melakukan pengukuran data terkait clinical outcomes yang seharusnya dilihat setelah 2 hari pasien menerima terapi antibiotik empiris sehingga parameter clinical outcomes yang digunakan pada penelitian ini adalah catatan dokter pada hari terakhir pasien rawat inap berupa membaik, belum membaik atau meninggal dan data diambil secara restrospektif sehingga informasi seperti perkembangan klinis hanya didapatkan sebagaimana yang tertulis pada rekam medis. Perlu dilakukan penelitian lebih lanjut yang juga memperhatikan faktor- faktor lain selain antibiotik seperti tingkat keparahan penyakit, adanya komorbiditas, dan adanya riwayat merokok yang dapat mempengaruhi clinical outcomes pada pasien dengan pneumonia.

\section{KESIMPULAN}

Terapi antibiotik empiris pada pasien dewasa dan lansia dengan pneumonia di Instalasi Rawat Inap RSUP Dr. Kariadi Semarang sebagian besar rasional berdasarkan kategori Gyssens. Beberapa antibiotik yang tidak rasional antara lain disebabkan oleh adanya antibiotik lain yang lebih efektif serta dosis dan interval antibiotik yang tidak tepat. Tidak terdapat hubungan antara rasionalitas terapi antibiotik empiris dengan clinical outcomes pada pasien yang menjalani rawat inap akibat pneumonia.

\section{DAFTAR PUSTAKA}

American Pharmacists Association, 2018. Lexicomp Drug Information Handbook - A Clinically Relevant Resource for All Healthcare Professionals, 26th ed. Wolters Kluwer.

Cillóniz, C., Cardozo, C., dan García-Vidal, C., 2018. Epidemiology, pathophysiology, and microbiology of community-acquired pneumonia. Annals of Research Hospitals, 2: 1-1.

Cilloniz, C., Martin-Loeches, I., Garcia-Vidal, C., San Jose, A., dan Torres, A., 2016. Microbial Etiology of Pneumonia: Epidemiology, Diagnosis and Resistance Patterns. International Journal of Molecular Sciences, 17: 2120.

Corrado, R.E., Lee, D., Lucero, D.E., Varma, J.K., dan Vora, N.M., 2017. Burden of Adult Community-acquired, Health-careAssociated, Hospital-Acquired, and Ventilator-Associated Pneumonia. Chest, 152: 930-942. 
Faizah, A.K. dan Putra, O.N., 2019. Evaluasi Kualitatif Terapi Antibiotik pada Pasien Pneumonia di Rumah Sakit Pendidikan Surabaya Indonesia 06: 5.

Kalil, A.C., Metersky, M.L., Klompas, M., Muscedere, J., Sweeney, D.A., Palmer, L.B., dkk., 2016. Management of Adults With Hospital-acquired and Ventilatorassociated Pneumonia: 2016 Clinical Practice Guidelines by the Infectious Diseases Society of America and the American Thoracic Society. Clinical Infectious Diseases, 63: e61-e111.

Kemenkes, 2018. Hasil Utama Riskedas 2018.

Lopardo, G.D., Fridman, D., Raimondo, E., Albornoz, H., Lopardo, A., Bagnulo, H., dkk., 2018. Incidence rate of communityacquired pneumonia in adults: a population- based prospective active surveillance study in three cities in South America. Open Access, 9.

Mandell, L.A., Wunderink, R.G., Anzueto, A., Bartlett, J.G., Campbell, G.D., Dean, N.C., dkk., 2007. Infectious Diseases Society of America/American Thoracic Society Consensus Guidelines on the Management of Community-Acquired Pneumonia in Adults. Clinical Infectious Diseases, 44: S27-S72.

Metlay, J.P., Waterer, G.W., Long, A.C., Anzueto, A., Brozek, J., Crothers, K., dkk., 2019.
Diagnosis and Treatment of Adults with Community-acquired Pneumonia. An Official Clinical Practice Guideline of the American Thoracic Society and Infectious Diseases Society of America. American Journal of Respiratory and Critical Care Medicine, 200: e45-e67.

Permenkes, 2011. Peraturan Menteri Kesehatan Republik Indonesia Nomor 2406/MENKES/PER/XII/2011 tentang Pedoman Umum Penggunaan Antibiotik.

RSUP Dr. Kariadi, 2018. Pedoman Penggunaan Antibiotik Terapetik, Edisi Ke-4.

Rumende, C.M., Chen, L.K., Karuniawat, A., Bratanata, J., Falasiva, R., Sitorus, T.P., dkk., 2019. Hubungan Antara Ketepatan Pemberian Antibiotik Berdasarkan Alur Gyssens dengan Perbaikan Klinis Pasien pada Pneumonia Komunitas. Jurnal Penyakit Dalam Indonesia, 6: 71.

Tejada, S., Vall d'Hebron Institut of Research (VHIR), Barcelona, Spain, CIBER de Enfermedades Respiratorias, CIBERES, Barcelona, Spain, Vall d'Hebron Institut of Research (VHIR), Barcelona, Spain, Rello, J., CIBER de Enfermedades Respiratorias, CIBERES, Barcelona, Spain, dkk., 2018. Community-Acquired Pneumonia in Adults: What's New Focusing on Epidemiology, Microorganisms and Diagnosis? Erciyes Tıp Dergisi/Erciyes Medical Journal, 40: 177-182. 